\title{
Expression of early placenta insulin-like growth factor in breast cancer cells provides an autocrine loop that predominantly enhances invasiveness and motility
}

\author{
B Brandt ${ }^{*}, D$ Kemming ${ }^{*}$ J Packeisen ${ }^{1}, R$ Simon $^{4},{ }^{2}$ Helms, U Feldmann ${ }^{1}$, \\ A Matuschek, C Kersting ${ }^{1}, B$ Hinrichs ${ }^{2}, J-M$ Bidart ${ }^{2}, D$ Bellet $^{3}, K$ Bartkowiak, \\ $N$ Dankbar, T Dittmar ${ }^{5}$, G Sauter $^{4}, W$ Boecker $^{1}$ and $H$ Buerger $^{1}$ \\ Institute of Tumor Biology, University Medical Center, Martinister. 52, 20246 Hamburg, Germany \\ ${ }^{1}$ Institute of Pathology, University of Münster, Münster, Germany \\ ${ }^{2}$ Institute of Pathology, Institute of Pathology, Cologne, Germany \\ ${ }^{3}$ Departement de Biologie Clinique, Institut Gustave-Roussy Villejuif and Faculté des Sciences Pharmaceutiques et Biologiques \\ de Paris, FRE2443 CNRS, Université René Decartes, Paris 5, France \\ ${ }^{4}$ Institute of Pathology, University of Basle, Basle, Switzerland \\ ${ }^{5}$ Institute of Immunology, University of Witten/Herdecke, Witten, Germany
}

(Requests for offprints should be addressed to B Brandt; Email: bu.brandt@uke.uni-hamburg.de)

(B Brandt \& D Kemming contributed equally to this work)

\begin{abstract}
Early placenta insulin-like growth factor (EPIL) is expressed by a subpopulation of the Her2-positive SKBR3 breast cancer cell line displaying high motility and transendothelial invasiveness in vitro, as recently shown by our group. As a consequence of this, we established cellular models by generating an EPIL-overexpressing SKBR3 cell line, knocked down EPIL by adding specific small interfering RNA (siRNA) to those cells and produced EPIL-enriched and depleted serum-free culture media. EPIL-expressing cells as well as EPIL-induced SKBR3 cells acquired a high capacity for transendothelial invasiveness. We observed a thin and outspread morphology caused by enhanced formation of lamellipodia, i.e. protrusions in the initial phase of motility. In parallel, Her2-positive MDAHer2 breast cancer cells also showed increased invasiveness when induced by EPILconditioned medium. A downstream signaling impact of EPIL could be observed in the form of reduced phosphorylation of Her2, erk1/2 and akt, while phospholipase $C_{\gamma} 1$ phophorylation remained unaffected. As an in vivo model for highly motile tumor cells, Paget's disease of the nipple showed simultaneous EPIL and Her2 expression upon immunohistochemical examination using specific antibodies. Such experimental data have been translated to a clinical setting by using a prognostic tissue microarray established from 603 breast cancer cases. Survival data analysis found a significant association between expression levels of EPIL and 5-year overall survival that was dose dependent: EPIL (negative) $84 \%$, EPIL (moderately positive) $77 \%$, EPIL (strongly positive) $48 \%(P<0.005)$. One particular subgroup $(7.6 \%$ of the cases with full clinical records) that comprised tumors simultaneously expressing EPIL and Her2 represented patients with the poorest 5-year overall survival. The results suggested that EPIL might be a cancer cell-produced growth factor that influences lateral Her2 signaling. Moreover, EPIL may be induced by factors apart from Her2 and may independently provide signaling for cancer invasion and motility.
\end{abstract}

Endocrine-Related Cancer (2005) 12 823-837 


\section{Introduction}

We have previously performed an in vitro selection of Her2-positive cell clones using an extravasation model and discovered that the insulin-like 4 (INSL4) gene was overexpressed in invasive subclones of SKBR3 cells (Roetger et al. 1998, Brandt et al. 2002). The INSL4 gene encodes peptides, designated as early placenta insulin like (EPIL), which are expressed predominantly in the trophoblastic cells of placenta during the first trimester of gestation (Chassin et al. 1995). EPIL expression was found to be similar to that described for several growth factors, including transforming growth factor- $\alpha$ and epidermal growth factor (EGF), which are expressed in the so-called 'invasive' phase of placental development (Bellet et al. 1997). Immunohistochemistry for EPIL using tissue microarrays (TMAs) indicated that simultaneous expression of both EPIL and Her2 was observed predominantly at the infiltrating border of the tumor which stained very positively for both molecules (Brandt et al. 2002). In contrast to the expression of the other family members, insulin-like growth factor (IGF)-I, -II and relaxin, EPIL peptides were exclusively expressed in the cancer tissue and not in the surrounding normal breast epithelium (Rasmussen \& Cullen 1998, Hombach-Klonisch et al. 2000, Brandt et al. 2002). As a result of this we established a cellular model to investigate the influence of EPIL action on invasiveness and cell motility by generating EPIL-overexpressing (SKBR3-EPIL) and EPIL knockdown (small interfering SKBR3) cell lines from parental SKBR3 wild-type cells. Following the hypothesis that autocrine factors can enhance cell invasion and motility, EPIL-enriched serum-free culture medium was produced from EPIL-overexpressing SKBR3-EPIL cells. SKBR3, MDA-468 and the genetically modified (for Her2 expression) MDAHer2 cell lines were subjected to this EPIL-conditioned medium in transendothelial invasion experiments. Furthermore, as a model disease for EPIL function in cellular motility, tissue samples from the nipples of patients suffering from Paget's disease were subjected to immunohistochemical staining for EPIL and Her2 using specific antibodies.

In order to evaluate the clinical significance of EPIL expression, 603 breast cancer tissues collected from patients with full follow-up records were assessed by an immunohistochemical technique performed on tissue arrays with antibodies specific for EPIL, Her2 and the estrogen receptor (ER). In general, and based on our previous results, we assumed that EPIL is a selfsufficient cancer cell factor that either influences lateral Her2 signaling or may be induced by factors other than
Her2 so that it provides additional as well as independent signaling for cancer invasion and motility.

\section{Materials and methods}

\section{Construction and cloning of a pro-EPIL expression plasmid}

An expression plasmid (pEPIL) coding for full-length INSL4 was constructed. The cDNA for INSL4 was generated by PCR using $5 \mu \mathrm{l}$ human placenta cDNA (BD Biosciences, Heidelberg, Germany) as a template. PCR was performed using $1.25 \mathrm{U}$ Pfu DNA polymerase (Promega, Mannheim, Germany), $12.5 \mathrm{nM}$ of each dNTP (MBI Fermentas, St Leon-Rot, Germany) and $50 \mathrm{pM}$ of the primers EPIL_Ex_For $\left(5^{\prime}-\mathrm{TTA} G\right.$ GATCCAGGATGGCCAGCCTG-3') and EPIL_Ex_ Rev (5'-TTATACCTCGAGATGTCCAGTCCATGATTAC-3') (Qiagen-Operon, Hilden, Germany) in a total volume of $50 \mu \mathrm{l}$. The conditions of the PCR were: $2 \mathrm{~min}$ at $94^{\circ} \mathrm{C}$, six cycles of $30 \mathrm{~s}$ at $94^{\circ} \mathrm{C}, 45 \mathrm{~s}$ at $51^{\circ} \mathrm{C}$, $2 \mathrm{~min}$ at $72^{\circ} \mathrm{C}$ and 35 cycles of $30 \mathrm{~s}$ at $94^{\circ} \mathrm{C}, 45 \mathrm{~s}$ at $60^{\circ} \mathrm{C}, 2 \mathrm{~min}$ at $72^{\circ} \mathrm{C}$ followed by a final extension for $7 \mathrm{~min}$ at $72^{\circ} \mathrm{C}$. Restriction sites (BamHI sense primer and $X h o I$ for antisense primers) are indicated by italic underlined characters. The insertion of the BamHI and XhoI (both from NEB, Frankfurt, Germany) digested EPIL cDNA into the mammalian expression vector pcDNA3.1(+) (Invitrogen, Karlsruhe, Germany); its cloning into E. coli Top10 $\mathrm{F}^{\prime}$ (Invitrogen) as well as plasmid preparation and sequencing were performed according to standard techniques. For sequencing, T7 promotor primer (Invitrogen) or one of the EPIL-specific primers EPIL_Rev1 (5'-TTTCTTCAATGATGGCTGCCC-3' $\left.{ }^{\prime}\right)$, EPIL_For 2 (5'-GACGTCCCAAAGAAATGGTGTC-3' ${ }^{\prime}$ or EPIL_Rev2 $\left(5^{\prime}\right.$-TGTCGTACCTAAGGCTTGGTCCA- $\left.3^{\prime}\right)$ (all Qiagen-Operon) were used.

\section{Cell culture and DNA transfection}

Breast cancer cell line SKBR3 (ATCC HTB-30) was obtained from the American Type Culture Collection (Rockville, MA, USA) and cultured as described previously (Brandt et al. 2002). The endothelial extracellular matrix functional assay contained human umbilical vein endothelial cells (HUVEC) which were isolated as described earlier (Roetger et al. 1998), and cultured in endothelial cell growth medium MV (PromoCell, Heidelberg, Germany) (Mock et al. 1999). Only cells before passage four were used in the assay. The cell line SKBR3-EPIL was generated by stable transfection of SKBR3 (ATCC HTB-30) with the 
pEPIL using lipofectamin 2000 (Invitrogen) according to the manufacturer's instructions. Forty-eight hours after transfection, $400 \mu \mathrm{g} / \mathrm{ml}$ G418 (Merck Biosciences, Schwalbach, Germany) was added to the media. Several G418-resistant and EPIL-expressing cell clones were isolated and pooled. The cell lines MDA-Neo and MDA-Her2 were generated as described previously (Brandt et al. 1999). For conditioning of medium by SKBR3-Neo and SKBR3-EPIL cells, fresh medium was added to the cells after reaching $60 \%$ confluency. After 3 days the medium was removed and sterile filtered before further usage. To remove EPIL from the medium, monoclonal anti-EPIL antibodies EPIL02 and EPIL08 (Mock et al. 1999) were mixed in equal concentrations and coupled to protein G-Dynabeads (Dynal, Hamburg, Germany) according to the manufacturer's instructions. Mouse IgG1 (MOPC21; Sigma, Steinheim, Germany) was used accordingly as a mock control. For each $\mathrm{ml}$ of Dynabeads $300 \mu \mathrm{g}$ antibody was used. Twenty milliliters of medium was depleted twice for $45 \mathrm{~min}$ each time with $100 \mu \mathrm{l}$ Dynabeads antibody conjugate at $7^{\circ} \mathrm{C}$. After removal of the antibody-coupled Dynabeads, the medium was sterile filtered before usage in the transmigration assay.

\section{RNA isolation}

Total RNA was extracted from breast cancer cell lines using the RNeasy Mini kit (Qiagen-Operon) according to the manufacturer's instruction manual.

\section{Real-time RT-PCR}

Total RNA was reverse transcribed using multiscribe reverse transcriptase and random hexamers (Applied Biosystems, Darmstadt, Germany) according to the manufacturer's instructions. The PCR were performed on an ABI PRISM 7900HT sequence detection system (Applied Biosystems) using the qPCR MasterMix Plus (Eurogentec, Seraing, Belgium). Each sample was thermocycled in triplicate using the EPIL-specific TaqMan Assays-on-Demand primers and probe (Applied Biosystems). Concentration variations between the samples were corrected by normalization to the amount of cDNA generated from 18S rRNA (predeveloped TaqMan assay reagents control kit; Applied Biosystems). Data analysis was carried out using SDS 2.1.1 software (Applied Biosystems).

\section{Fluorescence immunocytochemistry}

For immunofluorescence studies the cells were fixed in $4 \%(\mathrm{v} / \mathrm{v})$ formaldehyde in phosphate-buffered serum (PBS), permeabilized by $0.1 \%(\mathrm{v} / \mathrm{v})$ Triton X-100 and blocked with 10\% human AB-serum (AB-serum for serological reactions; Biotest, Dreieich, Germany) to inhibit non-specific staining. The cells were then incubated with the following antibodies: mouse monoclonal c-neu AB2 (for extracellular epitope binding) and AB3 (for intracellular epitope binding) (Merck Biosciences) and EPIL08 (Mock et al. 1999). The antibodies were visualized using polyclonal Alexa 594conjugated sheep-anti-mouse $\operatorname{IgG} \mathrm{F}\left(\mathrm{ab} \mathrm{b}^{\prime}\right)$ fragments (Molecular Probes, Leiden, The Netherlands) which were applied for $30 \mathrm{~min}$ at room temperature. Phalloidin-Texas Red was used for F-actin detection. After rinsing the slides with PBS, staining was evaluated using a BX 61 fluorescence microscope in combination with a DP 50 camera (both from Olympus, Hamburg, Germany). The software AnalySIS version 3.2 (Soft Imaging System, Münster, Germany) was used for image analysis, determination of cell areas and microscopic inspection.

\section{Endothelial extracellular matrix functional assay}

Cell culture inserts with $8 \mu \mathrm{m}$ porous polyethylene terephthalate (PET) membranes were placed in 12-well plastic tissue culture plates (Becton Dickinson Labware, Franklin Lakes, NY, USA). The membranes were coated with basement membrane extracellular matrix (ECM; Harbor Bio-Products, Norwood, MA, USA) at a concentration of $125 \mu \mathrm{g} / \mathrm{cm}^{2}$ by drying an appropriate ECM dilution overnight under a laminar flow hood with u.v. illumination. Dried ECM was re-hydrated with $500 \mu 1$ HUVEC culture medium for 30 min. HUVEC was seeded onto the coated membranes at a concentration of $2 \times 10^{5}$ cells/well. After culturing for 2 days at $37^{\circ} \mathrm{C}$ in a humidified atmosphere of $5 \% \mathrm{CO}_{2}$, HUVEC formed confluent monolayers. For the invasion assays of SKBR3, cells were harvested with $0.25 \%$ trypsin- 2 mM EDTA (Cambrex, Vervies, Belgium), adjusted to a density of $4 \times 10^{5}$ cells $/ \mathrm{ml}$ with serum-free invasion medium (Dulbecco's modified Eagles' medium (DMEM)) with $2 \mathrm{mM}$ L-glutamine, antibiotic drugs and $0.5 \%$ bovine serum albumin (BSA) (Sigma)), and $2 \times 10^{5}$ cells were placed onto the HUVEC monolayer on the ECM-coated membrane. The invasion medium was also placed into the wells under the bottom sides of the membranes. Cells were incubated for $12-24 \mathrm{~h}$ at $37^{\circ} \mathrm{C}$ in $5 \% \mathrm{CO}_{2}$. At the end of the invasion assay, the HUVEC monolayer and non-invading cells on the upper surface of the membrane were removed using cotton wool tips before the membranes were thoroughly rinsed with PBS ( $\mathrm{pH}$ 7.4). Invading cells on the uncovered lower 
side of the membrane were fixed in $4 \%$ paraformaldehyde and characterized by immunocytochemistry using two or three antibodies as described above.

\section{Immunoprecipitation and western blot analysis}

SKBR3-EPIL and -Neo cells were grown to $80 \%$ confluence in $75 \mathrm{~cm}^{2}$ bottles. Afterwards they were cultured for $24 \mathrm{~h}$ in invasion medium and then washed with chilled PBS. Cells were scraped from the bottles using a rubber scraper in $750 \mu$ lysis buffer containing $8 \mathrm{M}$ urea, $15 \mathrm{mM}$ EDTA, $25 \mathrm{mM}$ Tris and protease inhibitor (Roche). The lysate was incubated for $30 \mathrm{~min}$ at $4{ }^{\circ} \mathrm{C}$ on a horizontal shaker and centrifuged for $5 \mathrm{~min}$ at $10000 \mathrm{~g}$ at $4^{\circ} \mathrm{C}$. The DNA pellet was discarded and an aliquot was taken from the supernatant for protein determination (Lowry method). The solution was then adjusted so that it contained $2 \%$ SDS, $50 \mathrm{mM}$ dithiothreitol and a protein concentration of $1 \mathrm{mg} / \mathrm{ml}$ total protein. Ten microliter volumes of protein solutions were separated on a $7.5 \%$ SDSpolyacrylamide gel. Following electrophoresis, proteins were transferred onto a PVDF membrane (Roth, Karlsruhe, Germany) and non-specific binding sites were blocked using 6\% BSA in Tris-buffered saline (TBS) containing $0.1 \%$ Tween 20. Blots were probed with anti-Her2 (Ab3; Santa Cruz Biotechnology, Heidelberg, Germany), anti-phosphotyrosine (PY20), anti-PLC $\gamma 1$, anti-akt antibody (polyclonal), antiphospho-akt (Ser473) (monoclonal), anti-P44/42 MAP kinase antibody (polyclonal), anti-phospho-p44/p42 MAP kinase (Thr292/Tyr204) antibody (polyclonal) (Cell Signaling Technology, Inc., Beverly, MA, USA), and horseradish peroxidase-conjugated mouse antibodies (DAKO, Hamburg, Germany). The antibodies were used at a concentration of $0.1 \mu \mathrm{g} / \mathrm{ml}$. Bands were visualized using the highly sensitive enhanced chemiluminescence (ECL) system (Amersham/Pharmacia Biotech, Freiburg, Germany).

\section{Fluorescence immunoassay}

Determination of pro-EPIL level in culture supernatants was carried out as a two-site fluorescence immunoassay according to the IRMA protocol as previously described (Brandt et al. 2002). The immunoassay experiments were performed on preactivated hydrogel slides (HCX-Slides; Xantec Bioanalytics GmbH, Münster, Germany) (Mann et al. 2004) printing $120 \mathrm{pl}$ per spot monoclonal antibody (mAB) EPIL08 at a concentration of $500 \mu \mathrm{g} / \mathrm{ml}$ in $10 \mathrm{mM}$ 4-morpholine ethan sulfuric acid (Sigma-Aldrich), pH 6.0 using a GMS 417 ring-pin arrayer (Genetic
Microsystems Inc., Woburn, MA, USA). mAB EPIL08 was covalently coupled to the N-hydroxysuccinimide-activated carboxyl-functionalized hydrogel surface during $1 \mathrm{~h}$ of incubation at room temperature and $60 \%$ humidity. Any subsequent remaining reactive binding sites were quenched by shaking the slides in $1 \mathrm{M}$ ethanolamine (Sigma-Aldrich), $\mathrm{pH} 8.5$ for $40 \mathrm{~min}$. The quality of the spots (diameter $155-160 \mu \mathrm{m}$ ) and the efficiency of the immobilization procedure were controlled by scanning fluorescence marker spots $(500 \mu \mathrm{g} / \mathrm{ml}$ BSA-Oyster650 conjugate (Denovo Biolabels $\mathrm{GmbH}$, Münster, Germany) in $10 \mathrm{mM}$ MES, pH 6.0) using a microarray scanner (GMS 418; Genetic Microsystems Inc.). Immediately before use, each slide was rinsed with $1 \times \mathrm{TBS}, \mathrm{pH} 7.4$, containing $0.1 \%$ $(\mathrm{w} / \mathrm{v})$ BSA and than incubated at room temperature for $1 \mathrm{~h}$ with $2 \mathrm{ml}$ culture supernatant mixed with $1 \mathrm{ml}$ $1 \times$ TBS, pH 7.4, containing $0.1 \%(\mathrm{w} / \mathrm{v})$ BSA. Before use, incubation chambers were blocked with $1 \times$ TBS, $\mathrm{pH} 7.4$, containing $1 \%(\mathrm{w} / \mathrm{v})$ BSA for $0.5 \mathrm{~h}$. Blocking of slides was not necessary due to the bioinert characteristics of the hydrogel. After analyte incubation, the application of $4 \mu \mathrm{l} 100 \mu \mathrm{g} / \mathrm{ml} \mathrm{mAB}$ EPIL02Oyster650 conjugate was performed for $1 \mathrm{~h}$ in $2 \mathrm{ml} 1 \times$ TBS, $\mathrm{pH} 7.4$, containing $0.1 \%(\mathrm{w} / \mathrm{v})$ BSA for each slide. The slides were subsequently washed twice for $5 \mathrm{~min}$ in $1 \times$ TBS, $0.05 \%(\mathrm{v} / \mathrm{v})$ Tween $20, \mathrm{pH} 7.4$ and dried in a stream of compressed air. Scanning was carried out using the GMS 418 microarray scanner. Labeling of mAB EPIL02 was accomplished using the manufacturer's protocol (Denovo Biolabels $\mathrm{GmbH}$ ) with a reaction time of 20hairsp;min. To remove any excess fluorescent dye, antibodies were dialysed for $6 \mathrm{~h}$ against $1 \times$ PBS (Slide-A-Lyzer mini dialysis unit, 7000 Molecular Weight Cut Off; Pierce, Rockford, IL, USA). The activity of the conjugate was controlled using a surface plasmon resonance sensor (Guidi et al. 2001). Microarray slides were scanned at full laser power and $75 \%$ gain to avoid signal saturation from the marker spots. Image analysis of scanned slides was done using ImaGene 5 (Biodiscovery Inc., El Segundo, CA, USA). Data points were set in ratio to marker spots in the individual slide.

\section{siRNA design and synthesis}

Two siRNA sequences homologous for different regions of the EPIL mRNA sequence were synthesized by in vitro transcription using the Silencer siRNA construction Kit (Ambion, Huntingdon, Cambs, UK) according to the manufacturer's manual. DNA-oligonucleotide templates were purchased from Qiagen, as was the non-silencing control siRNA. siRNA sequences 
were as follows: siRNA EPIL1 sense r (reverse) (AAA GCC UAG CAG CAG AGC UGA), antisense r(AAU CAG CUC UGC UGC UAG GCU); siRNA EPIL2 sense $\mathrm{r}$ (AAG AUG GAC AAG CCU UAG GUA), antisense r(AAU ACC UAA GGC UUG UCC AUC); non-silencing control siRNA sense r(UUC UCC GAA CGU GUC ACG U)dTdT, antisense r(ACG UGA CAC GUU CGG AGA A)dTdT.

\section{siRNA sequence validation and optimization of concentration and time of incubation}

SKBR-3 cells were transfected in 24-well plates with lipofectamine 2000 according to the manufacturer's instructions using $1.5 \mu \mathrm{l}$ reagent per well (Invitrogen). The two EPIL-siRNA and the non-silencing siRNA were applied at different concentrations and cells were harvested after 6, 24, 48 and 72 h. EPIL expression was then determined by quantitative RT-PCR as described above. Using quantitative PCR the INSL4 gene expression levels was determined at the level of transcription, but not translation (EPIL).

\section{siRNA treatment of SKBR-3 for the invasion assay}

SKBR-3 cells were transfected as described above, but seeded at an amount of 250000 cells per well in six-well plates the day before transfection. The two siRNA were combined to reach a final siRNA concentration of $80 \mathrm{nM}$. Six hours after application of siRNA, cells were detached by trypsin/EDTA treatment and seeded onto the HUVEC layer of the invasion model. The invasion capacity of the cells was assessed at 12 and $24 \mathrm{~h}$ as described above.

\section{Paget's disease samples}

Ten cases of Paget's disease of the nipple were taken from the files of the Institute of Pathology, Cologne, Germany. All cases were associated with a simultaneous breast cancer. Three cases revealed the presence of a synchronous invasive carcinoma, one of these with a large ductal carcinoma in situ (DCIS) component, whereas the remaining seven cases were associated with pure DCIS.

\section{Tissue array construction, EPIL, Her2 and ER immunohistochemistry}

Formalin-fixed and paraffin-embedded tissue of 603 breast cancer cases having a median follow-up time of 68 months (1-176 months) were used for the production of a multitumor TMA. The tumors had been staged as lymph node negative (N0) in $49.9 \%$, T1 in
$34.5 \%, \mathrm{~T} 2$ in $47.1 \%, \mathrm{~T} 3$ in $6.2 \%$ and $\mathrm{T} 4$ in $12.3 \%$. ER was positive in $49.9 \%$ of the cases and $13.6 \%$ were positive for Her2 $(+2$ and +3$)$ as determined by the DAKO Her2 Scoring System.

Immunohistochemistry was performed on $4 \mu \mathrm{m}$ thick sections according to standard procedures. Antigen retrieval was done using a microwave for EPIL08 antibody for $15 \mathrm{~min}$ in citrate buffer, and for ER for $30 \mathrm{~min}$ in citrate buffer. No antigen retrieval procedure was required for Her2. The primary antibodies (EPIL mouse mAB EPIL08, kindly provided by J M Bidart (Bellet et al. 1997) and Her2 polyclonal DAKO A0485) were detected using an alkaline-phosphatase-antialkaline phosphatase method (APAAP) and a monoclonal APAAP complex $(1: 100$ in RPMI, $60 \mathrm{~min}$ at room temperature; DAKO). For ER immunohistochemistry, a standard indirect immunoperoxidase procedure (ABC-Elite; Vector Laboratories, Burlingame, CA, USA) was used in combination with the mAB ER ID5 (1: 1000; DAKO). Tumors with known positivity were used as positive controls. The primary antibody was omitted for negative controls. Tumors were considered positive for ER if an unequivocal nuclear positivity was seen in at least $10 \%$ of tumor cells. Quantification of immunohistochemical staining was performed according to conventional standards (Her2, 'Dako score'). Since, in the tumor spots, either almost all or no cells displayed an immunoreactivity for EPIL08, the staining intensity was only evaluated in a semi-quantitative manner (absent, weak, strong).

\section{Statistical analysis}

The correlation of EPIL expression with other markers of prognosis and differentiation in breast cancer was estimated by the Wilcoxon U-test and the Kruskall-Wallis test. Actual survival probabilities were calculated using the Kaplan-Meier method and the differences between the groups were estimated by the log-rank or Wilcoxon test. It should be noted that the number of patients in the Figures do not add up to 1468 because of missing data, e.g. due to unperformed or failed experiments, and patients who were lost in the follow-up. Multivariate analysis was performed using the Cox proportional hazards regression model.

\section{Results}

\section{Generation of high EPIL-expressing and EPIL knockdown SKBR3 cell lines}

In order to investigate whether a high and simultaneous expression of both INSL4 and ERBB2 (Her2) in 


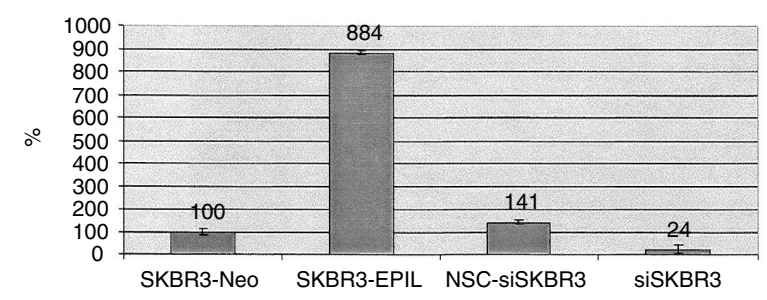

Figure 1 Measurement of INSL4 expression in SKBR3-Neo, SKBR3-EPIL, NSC-siSKBR3 and siSKBR3 by real-time PCR. The $\Delta c_{t}$ values for the SKBR3-Neo were set to $100 \% . \Delta c_{t}$ Values is the number of cycle reference gene 18 S-RNA minus number of cycles EPIL. The data for the other cell lines are shown as percentages of the $\Delta \mathrm{c}_{\mathrm{t}}$ values obtained for SKBR3-Neo ( \pm S.D.). PCR reactions were performed on an ABI PRISM $7900 \mathrm{HT}$ sequence detection system in triplicate using the EPIL-specific TaqMan Assays-on-Demand primers and probe. Concentration variations between the samples were corrected by normalization to the amount of cDNA generated from $18 S$ rRNA pre-developed TaqMan assay reagents control kit. Data analysis was done by SDS 2.1.1 software.

SKBR3 cells influences the formation of pre-migratory protrusions and transendothelial migration, we modified wild-type SKBR3 cells containing a low proportion of EPIL-expressing cells with an EPIL expression vector (SKBR3-EPIL). In order to control the specificity of the effect of the EPIL expression vector, a control cell line containing the empty expression vector was also established (SKBR3-Neo). To partly shut down the influence of EPIL on SKBR3 cells, an EPIL-specific siRNA was applied to the unselected cells (siSKBR3). A non-silencing negative control siRNA was also constructed (NSC-siSKBR3) to show whether the assessed effect of siRNA was specific to the EPIL knockdown.

The successful alteration of INSL4 expression in the modified cell lines SKBR3-EPIL, siSKBR3 and NSCsiRNA was confirmed by real-time PCR as shown in Fig. 1. As shown by our previous work, EPIL is secreted into the medium (Brandt et al. 2002) and for this reason the fluorescence immunocytochemical stain applying EPIL-specific antibody remained unchanged (data not shown ). Furthermore, real-time PCR confirmed that the ERBB2 mRNA level was not increased in SKBR3-EPIL. Moreover, no increased INSL4 mRNA levels were found in the previously described MDAHer2 cells. These cells had been transfected with a pcDNA3.1-based expression vector containing the full-length ERBB2 gene (Brandt et al. 1999, data not shown). These data support the assumption that EPIL and Her2 expression might be regulated over a broad range independently of the transcriptional level.

\section{EPIL changed the cell morphology of the Her2-positive cell line SKBR3 by increasing the formation of Her2-positive protrusions in serum-free medium}

SKBR3-EPIL cells displayed a higher proportion of flat cells expressing large protrusions in serum-free medium compared with SKBR3-Neo cells. Measurement of cell sizes by the AnalySIS software tool underlined this observation (SKBR3-EPIL mean area $2044 \pm 540 \mu \mathrm{m}^{2}$ and SKBR3-Neo $987 \pm 205 \mu \mathrm{m}^{2}$ $(P<0.01))$. Cell areas of transiently transfected siSKBR3 were smaller than those of SKBR3-Neo treated with non-specific siRNA (mean area $760 \pm$ $747 \mu \mathrm{m}^{2}(P<0.01)$ compared with SKBR3-Neo treated with non-specific siRNA).

The formation of more extended protrusions was observed more frequently and rapidly for SKBR3-EPIL cells than for SKBR3-Neo in serumfree medium, whereas the number of protrusions per cell remained unchanged (Fig. 2b). After $24 \mathrm{~h}$ of incubation, 1000 cells were counted in each well. In serum-free medium, SKBR3-EPIL cells with protrusions (mean $96 \pm 28$ ) were more than twice as common as SKBR3-Neo cells with protrusions (mean $45 \pm 6$ ). After 3 days the difference between SKBR3-EPIL cells and SKBR3-Neo cells in protrusion formation was smaller because the SKBR3-Neo cells now contained a low amount of naturally EPIL producing cells. The protrusions formed in serum-free medium displayed a high Her2 content as indicated by the green light emission observed upon immunofluorescence microcopy with an Her2-specific antibody that was bound to a secondary antibody coupled to Alexa 488 (Fig. 2a, for example see arrows).

\section{EPIL mRNA expression in SKBR3 cells increased transendothelial migration and reduced proliferation-associated signaling in Her2-expressing cancer cells}

Transendothelial invasion is a critical step in metastasis formation by hematogeneously spreading cancer cells. This complex process requires cell migration, a process which is accompanied by extreme shape changes. In order to prove the hypothesis that EPIL is involved in the enhanced invasiveness and motility of breast cancer cells, the breast cancer cell lines SKBR3-Neo, SKBR3-EPIL, siSKBR3 and NSC-siSBBR3 were subjected to the endotheliumextracellular matrix functional assay. In fact, the EPIL-transfected SKBR3-EPIL cell line gained a higher transendothelial invasiveness compared with the SKBR3-Neo cell line, whereas the siRNA-treated 
(a)
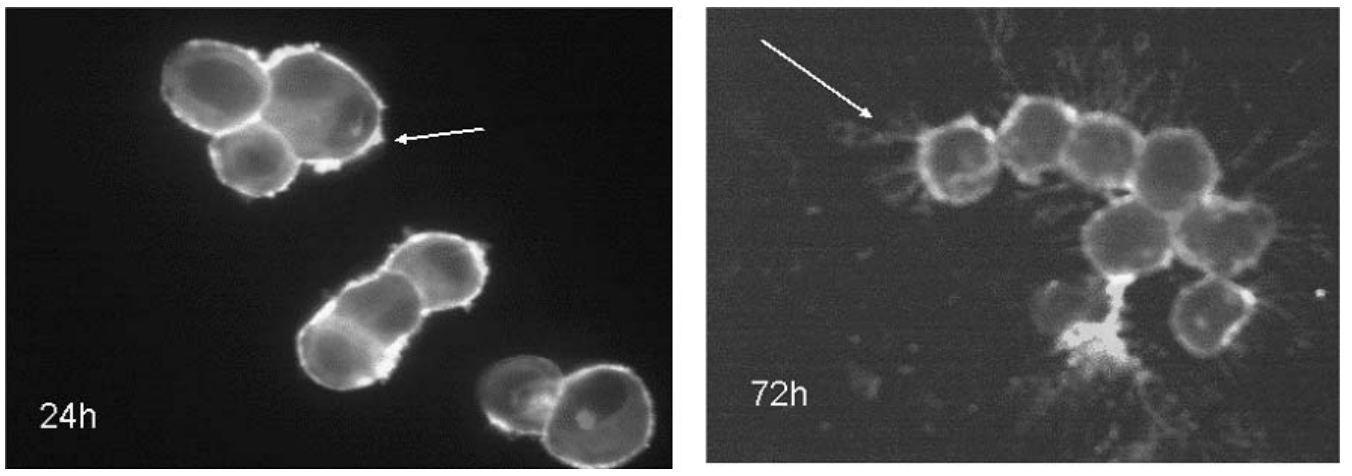

(b)

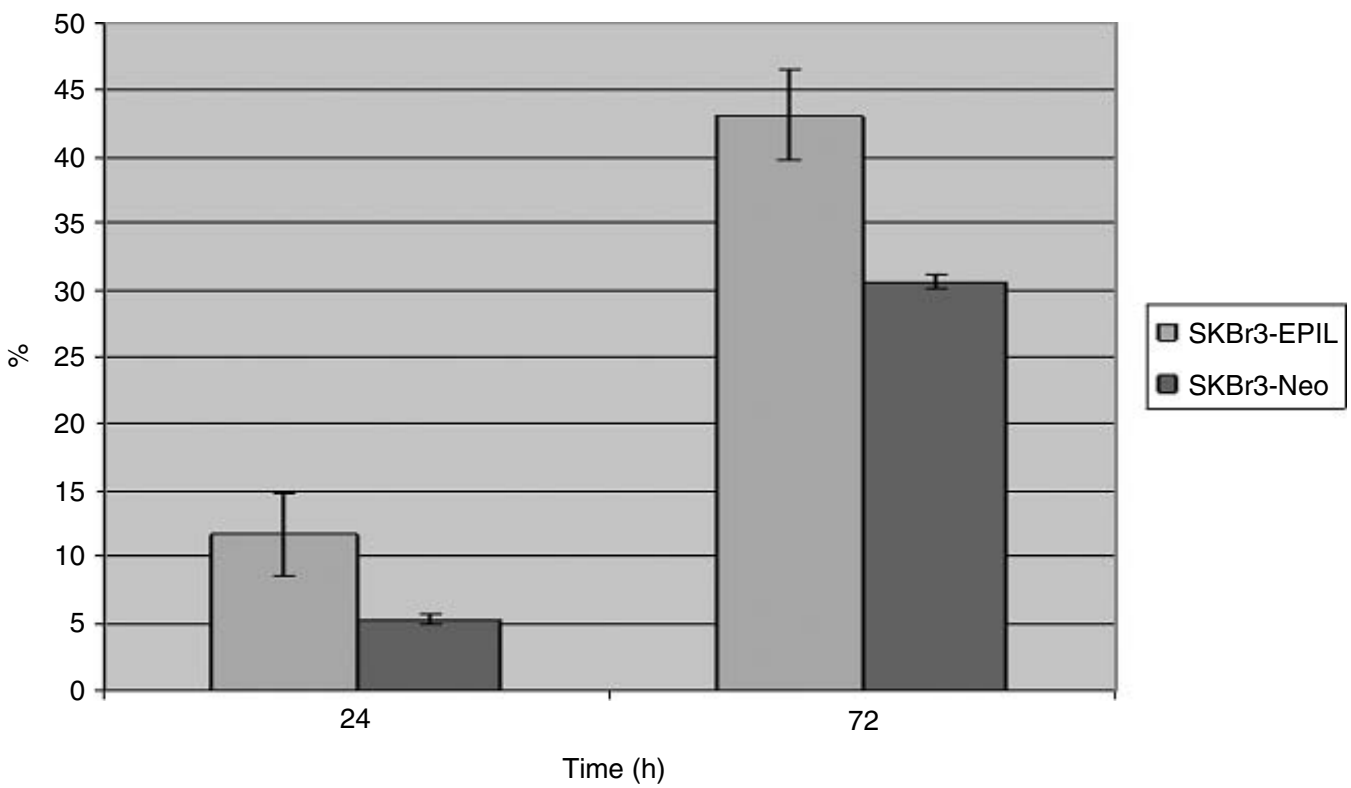

Figure 2 (a) Confocal laser scans by UltraView live cell imager (Perkin Elmer, Boston, MA, USA) of EPIL-expressing SKBR3 cells in serum-free medium after 24 and $72 \mathrm{~h}$ of culture time. The SKBR3-EPIL cells were simultaneously stained for Her-2 (green) and F-actin (red) by fluorescence dye coupled to secondary antibodies decorating antibodies against Her- 2 and by phalloidin coupled to Texas Red coupled to F-actin. The cells display Her2-positive formation of protrusions, lamellipodia, after $24 \mathrm{~h}$ which extend later to large ferny tillers. The morphology, especially of the protrusions, is extremely flat so that a transmission light detection is not shown. (b) Count of protrusions forming SKBR3-Neo and SKBR3-EPIL cells in serum-free medium after 24 and $72 \mathrm{~h}$ of culture time. On average, at least 1000 cells were counted in each well in triplicate. The fraction of cells showing protrusions was expressed as a percentage of the total number of counted cells ( \pm S.D.).

SKBR3 cells were significantly less invasive after down-regulation of EPIL in comparison with NSCsiSKBR3 cells transfected with a non-silencing siRNA control (Fig. 3a). However, a direct comparison between the SKBR3-EPIL cells and siSKBR3 cells was not appropriate because of the changes in morphology generated by the lipofectamine 2000 transfection reagent.

As shown in Fig. 3b, SKBR3-EPIL cells displayed a more extended and flat morphology than the other cell lines. Furthermore, the distribution of Her2 as stained by fluorescent dye-labeled specific antibodies was more diffuse over the entire cell body. SKBR3-EPIL, SKBR3-Neo and NSC-siRNA cells penetrated the $8 \mu \mathrm{m}$ pores less frequently than SKBR3-EPIL cells and the Her2 receptor was detected in intensively stained membrane-associated areas (Fig. 3b, sections C and D; see $\rightarrow$ ). Furthermore, applying immunoprecipitation and western blotting to SKBR3-EPIL and SKBR3Neo cells grown in serum-free medium revealed that 
B Brandt, D Kemming et al.: Influence of EPIL expression on cancer cell migration

(a)

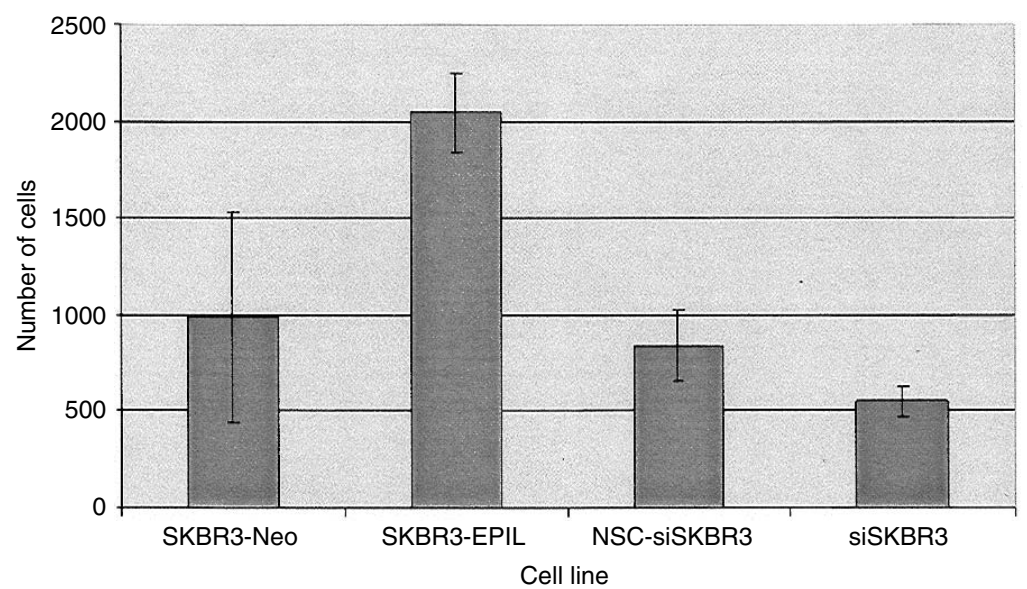

(b)
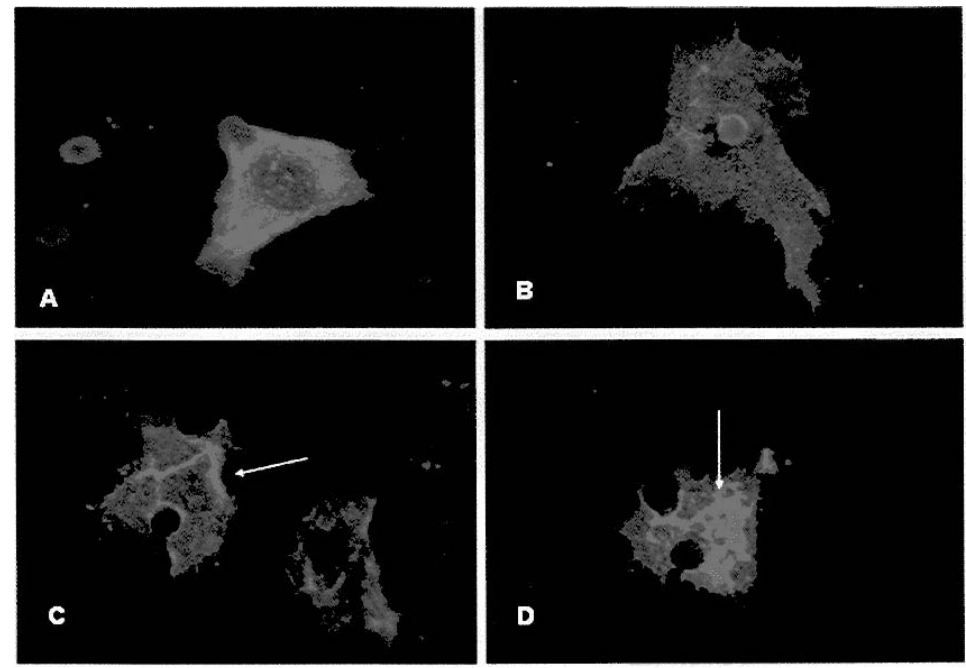

(c)

SKBR3-

EPIL Neo

\begin{tabular}{|c|c|c|c|}
\hline total Her2 & 테 & 6 & $185 \mathrm{kDa}$ \\
\hline ptyr Her2 & eat & $=$ & \\
\hline total PLC $\gamma 1$ & tas & 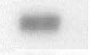 & $155 \mathrm{kDa}$ \\
\hline p-tyr PLC $\gamma 1$ & $\theta$ & $\infty$ & \\
\hline total erk $1 / 2$ & $\bar{m}$ & 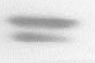 & 42 and $44 \mathrm{kD}$ ? \\
\hline p-tyr erk1/2 & $=$ & $=$ & 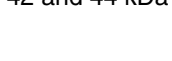 \\
\hline total Akt & $=$ & 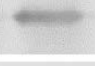 & $60 \mathrm{kDa}$ \\
\hline p-ser478 Akt & $\longrightarrow$ & $=$ & \\
\hline
\end{tabular}


Her2 receptor phosphorylation was decreased, phosphorylation of erk $1 / 2$ and akt (Ser473) was decreased while PLC $\gamma 1$ phosphorylation remained unchanged in comparison with the total protein expression (Fig. 3c).

\section{Conditioned medium containing secreted EPIL increased the transendothelial invasiveness of SKBR3 and MDAHer2 cells significantly}

In order to prove the working hypothesis that EPIL provides an autocrine loop for enhancement of the transendothelial invasiveness of breast cancer cells, the breast cancer cell line SKBR3-Neo was cultured with medium containing secreted EPIL. To this end, cells were subjected to the endothelium-extracellular matrix functional assay in which serum-free invasion medium was taken from SKBR3-EPIL in culture (for details see section on Cell culture and DNA transfection).

As shown in Fig. 4a, fluorescence immunoassay using specific anti-EPIL mABs confirmed that the medium was enriched for EPIL and depleted after antibody-based immunoprecipitation. To demonstrate the specificity of the EPIL-directed antibodies, a non-binding antibody (MOPC21) of the isotype was used for depletion. SKBR3-Neo in EPIL-conditioned medium acquired a significantly higher transendothelial invasive activity compared with SKBR3-Neo cells cultured in anti-EPIL mAB EPIL-depleted conditioned medium $(P<0.001, t$-test $)$ and in unconditioned serum-free invasion medium. Similar results were obtained for the SKBR-Neo cells cultured in MOPC21-treated medium (Fig. 4b, $P<0.001, t$-test). Furthermore, we also treated the MDAHer2 cell line, harboring an Her2-expression vector, and the parental cell line MDANeo, containing the empty control vector, with SKBR3-EPIL-conditioned medium and SKBR3-Neo-conditioned medium. EPIL-conditioned medium also increased transendothelial invasiveness of the Her2-overexpressing cell line MDAHer2 significantly (MDAHer2 EPIL-conditioned medium: mean $473 \pm 83$ cells; non-conditioned medium: mean $312 \pm 40$ cells; $P<0.05, t$-test); whereas no significant results were obtained for the low Her2-expressing and poorly invasive parental cell line MDANeo (MDANeo EPIL-conditioned medium: mean $107 \pm 15$ cells; non-conditioned medium: mean $85 \pm 25$ cells; $P=0.023, t$-test $)$.

\section{The model disease for cell motility: Paget's disease of the nipple}

As a model for a disease containing highly motile cells, we examined breast tissues from patients suffering from Paget's disease of the nipple by immunohistochemistry, using the monoclonal anti-EPIL antibody. Co-expression of high levels of EPIL and Her2 were observed in highly motile Paget's cells (Fig. 5a and b). Whereas the expression of Her2 was always moderate to strong, the expression of EPIL was predominantly moderate. Interestingly, a high expression level of EPIL was seen in cases with a moderate expression of Her2 (Fig. 5c).

\section{Immunohistochemistry on prognostic tissue arrays}

On the prognostic tissue microarrays which represented 1468 invasive breast cancer cases, $48 \%$ were negative, $48.7 \%$ stained moderately positive $(+)$ and

Figure 3 (a) Migration and invasion capacity of SKBR-Neo, SKBR3-EPIL, NSC-siSKBR3 and siSKBR3 breast cancer cell lines as determined by the endothelial-extracellular matrix functional assay in relation to pro-EPIL expression. The number of cells which penetrated the endothelium-extracellular matrix assay within $12 \mathrm{~h}$ (mean \pm S.D.). (b) Fluorescence microscopy of $(A)$ SKBR3-Neo, (B) SKBR3-EPIL, (C) NSC-siSKBR3 and (D) siSKBR3 cells passing through the $8 \mu \mathrm{m}$ pores and settling down on the uncovered site of the PET membrane after invasion of the endothelial-extracellular matrix layer. The cells were stained for Her-2 (red) by fluorescence dye coupled to secondary antibodies coupled to antibodies against Her-2. Wild-type SKBR3-Neo and nonsense siRNA-treated cells NSC-siSKBR3 cells displayed a membrane-located Her-2 staining (A and C). In contrast, invasive SKBR3-EPIL cells showed a spread-out morphology and diffuse Her-2 staining all over the cytoplasm (B). This phenotype is reversed in the siRNA-treated siSKBR3 cells which showed a shrunken morphology with a dense Her-2 staining in distinct areas of the cells (D, arrow). As already mentioned in our previous publications (Brandt et al. 1999) the cell morphology is extremely flat and as such no transmission light detection picture could be shown. (c) Comparison of phosphorylation levels of Her-2, PLC $\gamma 1$, erk1/2 and akt in SKBR3-Neo and SKBR3-EPIL cells by western blot analysis using phosphotyrosine (ptyr) and phosphoserine (pser) specific antibodies. For both experiments, the Her-2-expressing cell lines were cultured in serum-free medium for $24 \mathrm{~h}$. Cells were washed and solubilized, and protein concentrations were equalized. After SDS-PAGE, proteins were blotted on a PVDF membrane $(0.45 \mu \mathrm{m}$; Millipore, Schwalback, Germany). Protein detection was performed with primary antibodies against the assigned proteins. Secondary antibodies are coupled to horseradish peroxidase and visualization was carried out with the ECL system. 

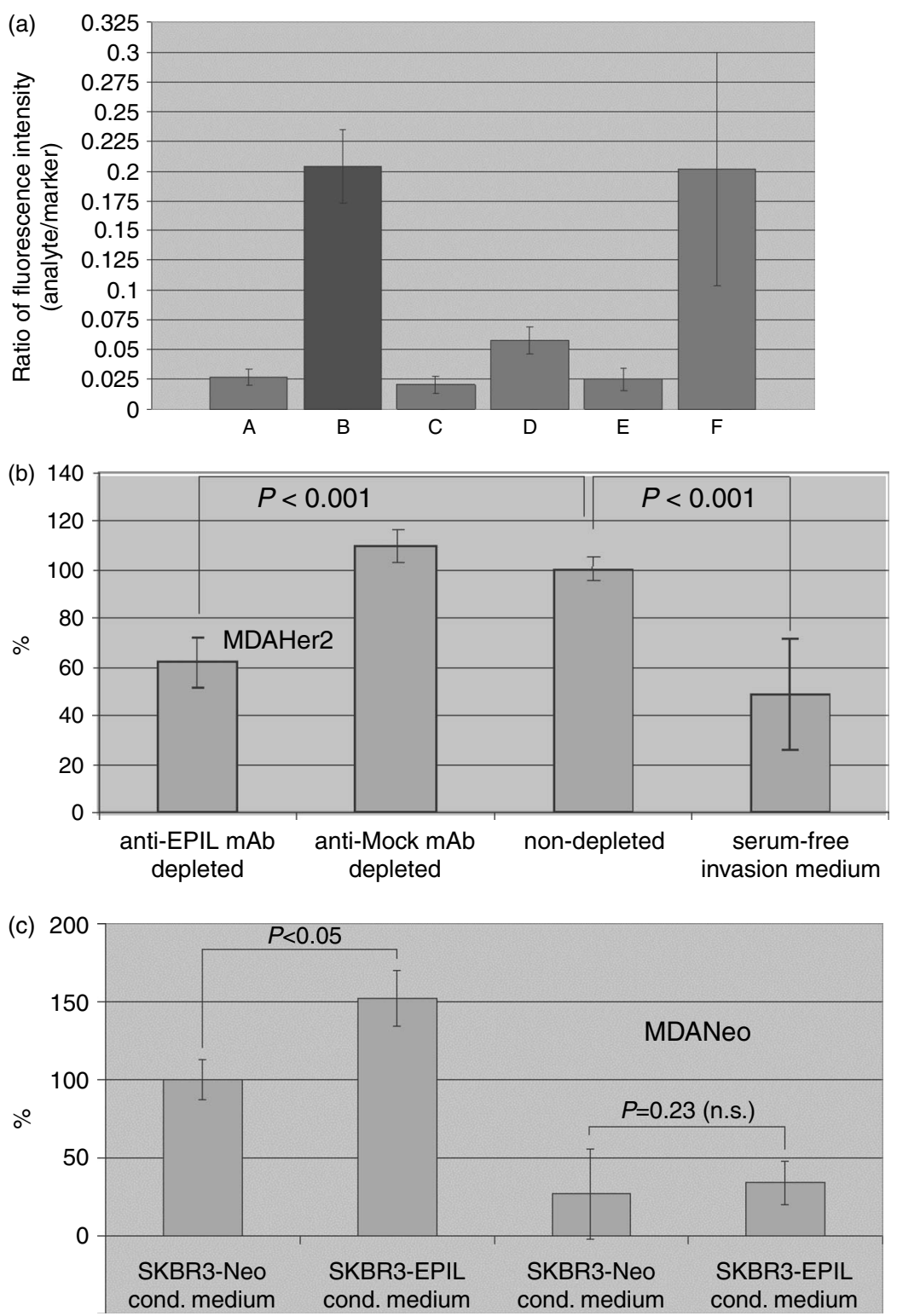

Figure 4 (a) Semi-quantitative determination of pro-EPIL level in culture media conditioned by SKBR3-Neo and SKBR3-EPIL. mAB EPIL08 was immobilized in six spots per hydrogel-coated slide. Microarray slides were incubated with different conditioned culture media followed by mAB EPIL02-Oyster650 conjugate. The scanned fluorescence intensity of analyte spots was plotted against marker spots intensity $(n=3$, mean \pm S.D.). Bars $A, C$ and $E$ represent values from media conditioned by SKBR3-Neo, bars $B, D$ and $F$ indicate media conditioned by SKBR3-EPIL. Bars $A$ and $B$ show the EPIL level in culture media treated with anti-MOCK antibody-coated magnetic beads (negative control). Depletion of EPIL from conditioned media by anti-EPIL02/08 antibody-coated microbeads is represented by bars C and D. Non-depleted media are indicated by bars E and F. (b) SKBR3-Neo transendothelial invasiveness in SKBR3-EPIL-conditioned medium determined by the endothelial-extracellular matrix functional assay in relation to pro-EPIL expression. Percentage of cells which penetrated the endothelium-extracellular matrix assay within $12 \mathrm{~h}$ (mean \pm S.D.) in relation to SKBR3-Neo cells in non-depleted SKBR3-EPIL-conditioned medium. The number of penetrating SKBR3-Neo cells in non-depleted SKBR3-EPIL-conditioned medium was set to $100 \%$ (mean $3380 \pm 102$ cells (S.D.)). Experiments were performed four times for each medium condition. (c) MDAHer2 and MDANeo transendothelial invasiveness in SKBR3-EPIL and SKBR3-Neo-(non)-conditioned (cond.) medium determined by the endothelial-extracellular matrix functional assay in relation to pro-EPIL expression. Percentage of cells which penetrated the endothelium-extracellular matrix assay within $12 \mathrm{~h}$ (mean \pm S.D.) in relation to MDAHer2 cells in non-conditioned medium. The number of penetrating MDAHer2 cells in SKBR3-Neo-conditioned medium was set to $100 \%$ (mean $312 \pm 40$ cells (S.D.)). Experiments were performed three times for each medium condition. 
(c)

(a)

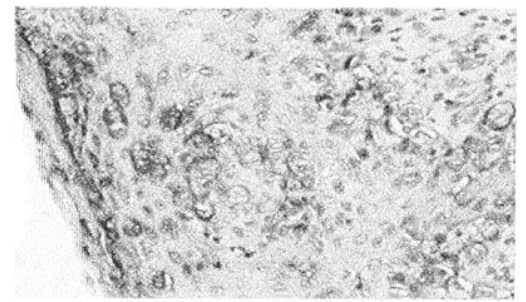

(b)

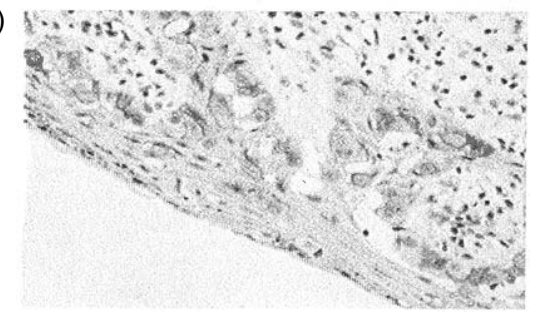

\begin{tabular}{|c|c|c|}
\hline Patient no./ & Her2 & EPIL \\
\hline 1 & $2+$ & high \\
\hline 2 & $1+$ & high \\
\hline 3 & $3+$ & intermediate \\
\hline 4 & $3+$ & high \\
\hline 5 & $3+$ & intermediate \\
\hline 6 & $3+$ & intermediate \\
\hline 7 & $2+$ & high \\
\hline 8 & $3+$ & high \\
\hline 9 & $3+$ & intermediate \\
\hline 10 & $3+$ & high \\
\hline
\end{tabular}

Figure 5 Paget's disease as an in vivo model for breast cancer cells with high motility. As an in vivo model we examined tissue from patients suffering from Paget's disease of the breast by immunohistochemistry using a monoclonal anti-EPIL antibody. Co-expression of high levels of EPIL and Her2 were observed in highly motile Paget's cells. (a) Immunohistochemical staining for EPIL, (b) immunohistochemical staining for Her2 and (c) chart for the staining scores of EPIL (high, intermediate) and Her2 (DAKO score $0,1+, 2+, 3+$ ) in tissue sections from ten cases of Paget's disease.

$3.4 \%$ stained strongly positive for EPIL $(++)$. EPIL expression was statistically significantly associated with a higher tumor stage (pT1 vs pT2, $P<0.05$ ), lymph node $(\mathrm{N})$ involvement $(\mathrm{N}-$ vs $\mathrm{N}+, P<0.001)$, and a negative ER status $(\mathrm{ER}-\mathrm{vs} \mathrm{ER}+, P<0.05)$. Survival data analyzed by Kaplan-Meier test revealed a significant association between expression levels of pro-EPIL determined by immunochemistry and 5-year overall survival which was dose-dependent: EPIL (-), $84 \%$; EPIL $(+), 77 \%$; EPIL $(++), 48 \%(P<0.001$; Fig. 6a). This relationship also held true in subgroups with different Her2/pro-EPIL co-expression patterns, including (A) Her $\leq+1 / \operatorname{EPIL}(-) \quad(n=224)$, (B) Her $2 \geq+2 /$ EPIL $\quad(-) \quad(n=41), \quad($ C $)$ Her $2 \leq+1 /$ $\mathrm{EPIL} \geq(+)(n=292)$ and (D) Her $2 \geq+1 / \mathrm{EPIL} \geq(+)$ $(n=46) \quad(P<0.001$; Fig. 6b). Patients with a poor prognosis were also represented by subgroups B and C. The tumors in subgroup $\mathrm{C}$ expressed only EPIL peptide and Her2 less equal expression score +1 . In node-negative patients, a similar trend was observable in overall survival (Os), but this was of only borderline significance. Multivariate analysis with Cox's model showed that EPIL is only one independent prognostic indicator besides node status $(\mathrm{pN})$, tumor stage $(\mathrm{pT})$ and grading $(\mathrm{G})$ when Her2 is not included in the model (OS: pro-EPIL: risk ratio $(\mathrm{RR})=1.4, P<0.05$;
pN: RR 2.5, $P<0.0001 ; \mathrm{pT}: \mathrm{RR}=1.9, P<0.0001$; $\mathrm{G}: \mathrm{RR}=1.7, P<0.0001$ ).

\section{Discussion}

Metastasis is the major cause of breast cancer-related death. The formation of metastases requires complex capabilities of tumor cells which can be subdivided into multiple, partially independent steps, and which includes the acquisition of the ability to migrate. Since the majority of breast cancer metastases occur with varying latency even in primary lymph nodenegative primary breast cancer, therapeutic interventions that target tumor cell migration capabilities might be key to preventing the formation of metastases, especially in subtypes with low proliferative activity.

We were able to show recently that highly transendothelial invasive subpopulations within the Her2positive SKBR3 breast cancer cell line exist that are characterized by an increased expression of EPIL, an IGF protein. Furthermore, EPIL expression was associated with a decreased proliferative capacity as shown in vitro by growth curves and in vivo by Mib-1 immunohistochemistry in invasive breast cancer tissue (Brandt et al. 2002). 
(a)

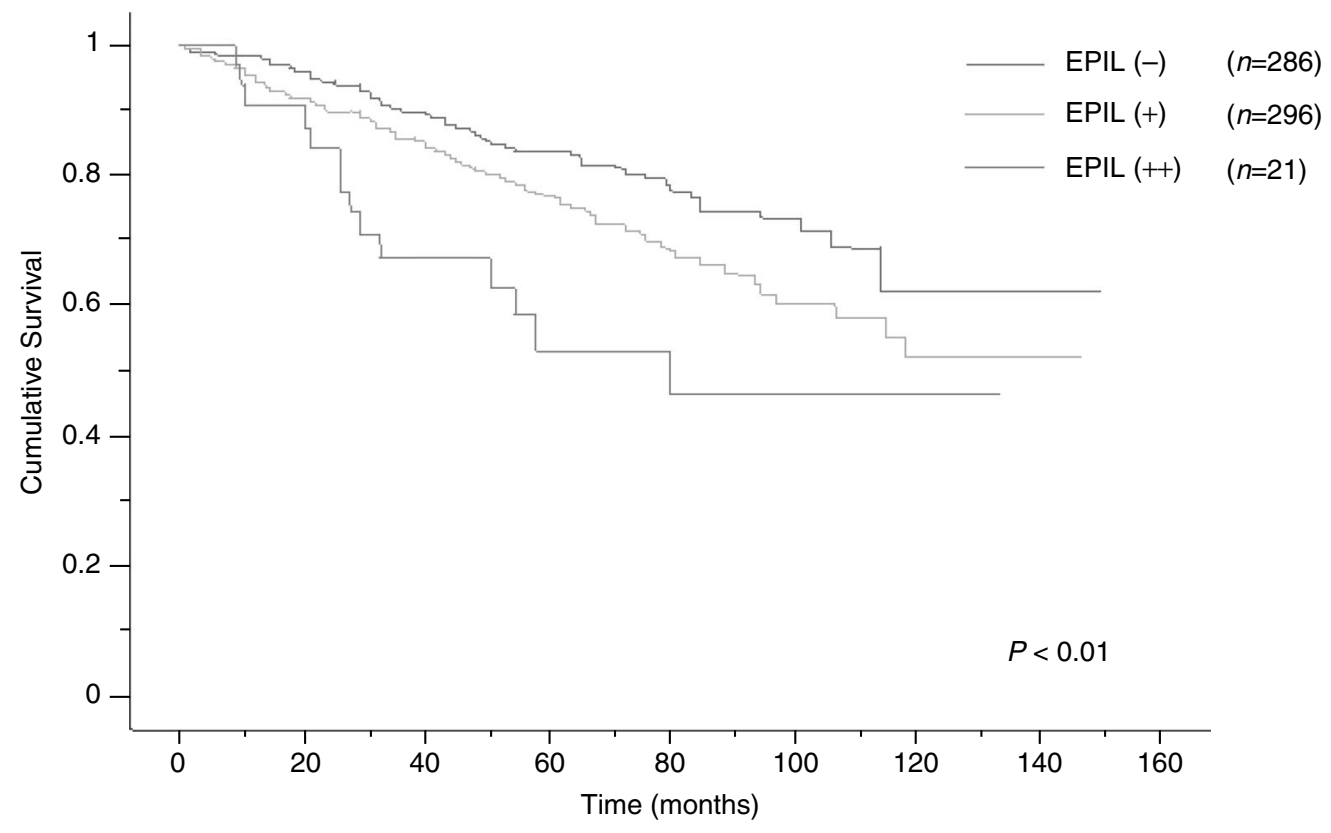

(b)

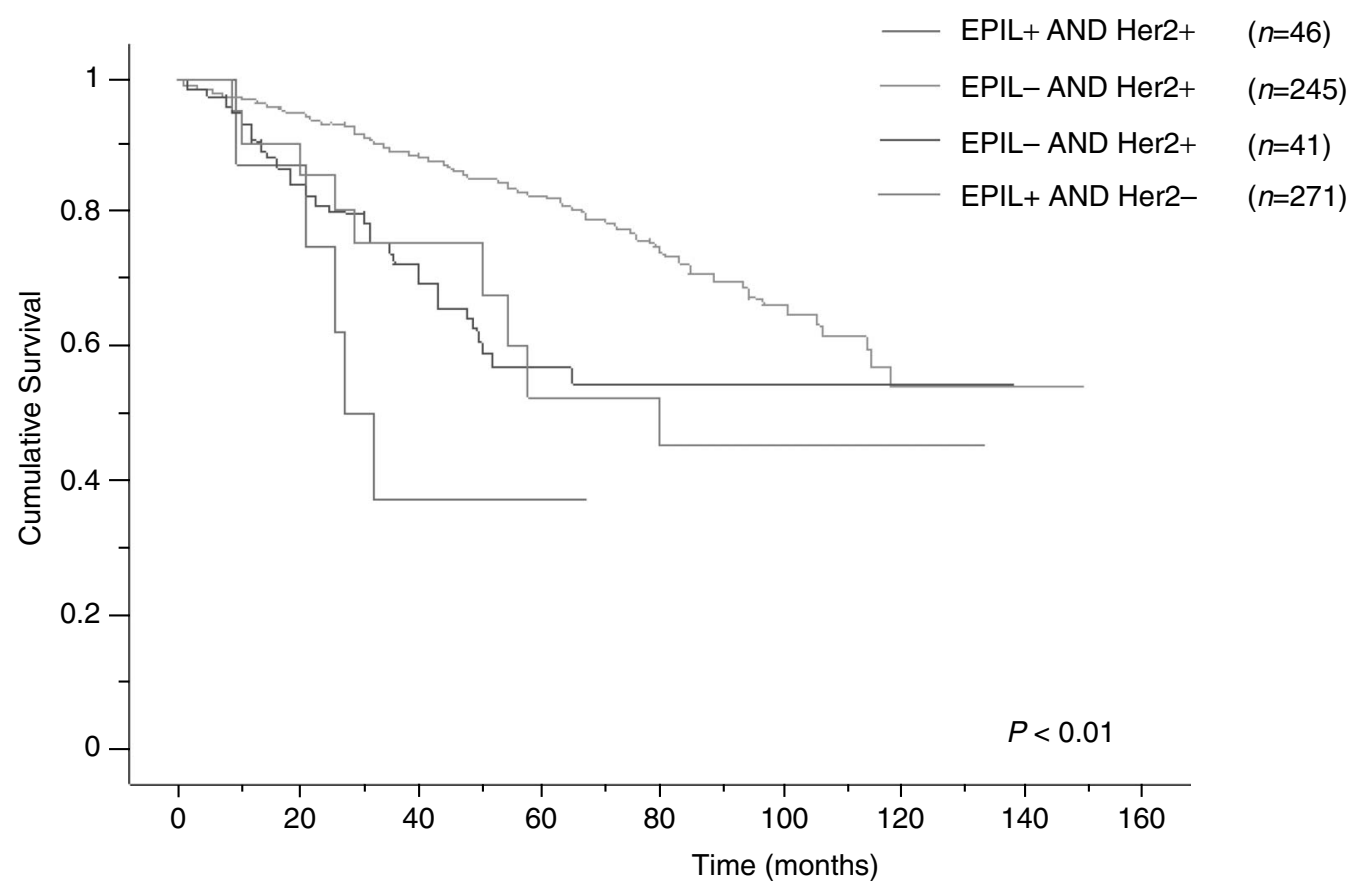

Figure 6 (a) Kaplan-Meier cumulative survival plot for 1-month survival demonstrating a significant relationship between EPIL expression and overall survival $(P=0.0014)$. (b) Kaplan-Meier cumulative survival plot for 1 -month survival categorized for EPIL and Her2 expression and determined by immunohistochemistry. Shortest overall survival is demonstrated for the $\mathrm{EPIL}+/$ Her2 + subgroup as well as for the EPIL $+/$ Her2 - subgroup $(P<0.001)$.

The expression of Her2 is associated in experimental settings with an inducible motile phenotype and clinically with a poor prognosis for breast cancer. In this case, the orphan receptor Her2 functions as an integrator of signals rendered to the cell by different growth factors and their receptors, e.g. EGF and 
IGF-I (Graus-Porta et al. 1997, Brandt et al. 1999, Balana et al. 2001). In SKBR3 cells, the ERBB2 gene is amplified and the Her2 receptor is strongly overexpressed whereas the preferred heterodimerization partners EGF receptor (EGFR) and the other receptors of the erbB family are poorly expressed. It therefore represents a model with which to study the influence of other molecules that potentially interfere with Her2 receptor function.

In order to determine whether EPIL might also be a coactivator of Her2 we tried to establish cellular models in which inducible invasiveness could be correlated with differences in EPIL expression levels. As such, SKBR3 cells were transfected with the plasmid vector pCDNA3.1 $(+)$ containing the fulllength wild-type human INSL4 cDNA and, in a second experiment, SKBR3 anti-EPIL siRNA. The EPILtransfected SKBR3 cell line turned out to display large protrusions in serum-free medium more rapidly and more frequently compared with the other three cell lines. Indeed, the formation of protrusions, i.e. lamellipodia, is a phenotypic step necessary for the migration and invasion of tumor cells (Dittmar et al. 2002). Furthermore, these EPIL-transfected cells acquired an increased transendothelial invasiveness compared with the SKBR3-Neo control cells, whereas the transiently siRNA-treated SKBR3-EPIL cells were significantly less invasive after down-regulation of EPIL in comparison with NSC-siSKBR3 (Fig. 3a and b). The empty vector-transfected cell line SKBR3Neo displayed the same transendothelial invasiveness compared with its parental wild-type cell line SKBR3 (Fig. 3a and b), as did SKBR3 cells transfected with a non-silencing siRNA control.

Furthermore, we produced an EPIL-conditioned invasion medium by growing the high EPIL expressers SKBR3-EPIL in serum-free DMEM. Similar to the EPIL intracellular expression approach, SKBR3-Neo cells cultured with the EPIL-conditioned medium or MOPC21-treated medium acquired a significantly greater transendothelial invasiveness compared with SKBR3-Neo cells cultured in unconditioned serumfree invasion medium, or in anti-EPIL mAB EPILdepleted conditioned medium (Fig. 4b). In analogy with the EPIL-expressing SKBR3-EPIL cells, the SKBR3-Neo cells displayed a more extended and flat morphology in EPIL-conditioned medium than they did in normal and depleted medium. We also subjected MDAHer2 cells, containing an Her2-expression vector, and the Her2-negative parental cell line MDANeo containing the empty control vector, to the conditioned media. As shown in Fig. 4c, the transendothelial invasiveness of MDAHer2 was significantly enhanced in EPIL-conditioned medium compared with the invasiveness seen in medium obtained from SKBR3-Neo cells. In contrast, the MDANeo cell line showed no significant increase at all (Fig. 4c). These data are compatible with the assumption that EPIL might be a self-sufficient cancer cell factor that also contributes laterally to Her2 tyrosine kinase receptor signaling. This was further supported by the observation that the mean phosphorylation of Her2 but not Her2 expression was lower in the SKBR3-EPIL than it is in the wild-type cells, as shown by Western blot analysis. A lateral transmission from insulin growth factors was described for Her2 and for the Her2 homologue EGFR. In this process, signals are transduced in a hierarchical manner from IGF-I receptor to Her2 and EGFR (Roundabush et al. 2000, Balana et al. 2001, Gilmore et al. 2002). As expected for growth factors, the signaling of the IGF-I led to growth activation and an inhibition of apoptosis that could be interrupted at the EGFR level (Gilmore et al. 2002). The loop suggested here consisting of EPIL and Her2 might regulate cancer cell growth as shown by the in vitro data from erk $1 / 2$ and akt phosphorylation as well as the already published reduced Mib-1 expression in breast cancers expressing both EPIL and Her2 molecules (Brandt et al. 2002). The PLC $\gamma 1$ pathway which was described as being important for migratory signals remains steadily activated and might also be able to transduce survival signals via inositol phosphate isomeres (Brandt et al. 1999, Irvine \& Schell 2001, Dittmar et al. 2002, Katterle et al. 2004). Nevertheless, the receptor(s) for EPIL has to be discovered before a kinetic model for EPIL signaling could be investigated. This, however, was beyond the scope of this study.

As a model disease for highly motile cells, we investigated ten cases of Paget's disease of the nipple, which is known to be a high Her2-expressing tissue (Schelfhout et al. 2000). Paget's disease is defined as an intraepidermal proliferation and spreading of malignant epithelial cells. In the vast majority of cases it is combined with a ductal carcinoma in situ or an invasive breast cancer. The malignant cell population in the epidermis is therefore interpreted as a non-invasive spreading of the DCIS along the major mammary ducts into the epidermis, an act requiring a high degree of cellular motility without any invasive properties, since the basement membrane is not affected by the tumor cells. Consistent with the literature, our results showed that Paget's cells in the majority of cases feature a strong positivity for Her2 (De Potter \& Schelfhout 1995). In addition, all 
cells also revealed a moderate to strong co-expression of EPIL. Interestingly, the highest levels of EPIL expression were observed in two cases that demonstrated only a moderate expression of Her2. Since we were recently able to demonstrate that EPIL is secreted by tumor cells, the expression of EPIL might represent an autocrine effect in this disorder alongside a possible keratinocyte-mediated paracrine effect as demonstrated elsewhere (Schelfhout et al. 2000).

To address the question as to whether there is an enhancer effect of EPIL in Her2-positive breast cancer cells, we comprehensively evaluated the clinical significance of EPIL in a set of 1468 primary breast cancers with attached follow-up data. We found statistically significant associations between pro-EPIL expression and lymph node involvement $(P<0.001)$, ER expression $(P<0.05)$ and overall survival $(P<$ $0.0001)$. Multivariate analysis considering pT stage, $\mathrm{pN}$ stage and grading was even able to confirm proEPIL expression as an independent prognostic indicator of outcome if Her2 was omitted from the model. Taken together, these data suggest that EPIL might be a cancer cell-produced growth factor that influences lateral Her2 signaling.

EPIL expression was compared with Her2 and ER expression using the same TMAs. Co-expression of both Her 2 and pro-EPIL was found in 54 cases (3.4\%), although isolated expression of either EPIL or Her2 was also found in $565(51.2 \%)$ and $141(21 \%)$ cases respectively. This suggests that pro-EPIL may be induced by factors other than Her2. The lower rate of highly positive samples for pro-EPIL as compared with the previous study (Brandt et al. 2002) may be explained by the fact that immunohistochemistry is a semiquantitative method, or the fact that a much higher number of samples was investigated in this study. The fact that in a series of over 1000 samples pro-EPIL expression was displayed in over $51 \%$ of them is striking. Moreover, the clear-cut differences in prognosis between pro-EPIL-/Her2- (5year survival: $83 \%$ ) and pro-EPIL $+/$ Her $2+$ tumors (5-year survival: $38 \%$ ) can be interpreted as a clinical confirmation of the in vitro-based hypothesis that the co-expression of both proteins determines a highly aggressive, motile breast cancer phenotype. Importantly, pro-EPIL/Her2-co-expression identified high-risk patients even in node negative patients.

In summary, our data have shown that EPIL is worth investigating in future studies to discover the putative receptor(s) and binding proteins, and to elucidate plausible mechanisms of induction of intracellular signaling so that future therapeutic targets can be identified.

\section{Acknowledgements}

The authors would like to thank Hildegard Schütte for the HUVEC cell preparation and Mathias Isakiewicz for his excellent technical assistance. This study was supported by grants from Deutsche Forschungsgemeinschaft BR 1756/5-2, Fritz-Bender-Foundation and Interdisziplināres Zentrum fūr Klinische Forschung der Universitāt (IZKF) Münster.

\section{References}

Balana ME, Labriola L, Salatino M, Movsichoff F, Peters G, Charreau EH\& Elizade PV 2001 Activation of erbB-2 via hierarchical interaction between erbB-2 and type I insulin-like growth factor receptor in mammary tumor cells. Oncogene $203434-3447$.

Bellet D, Lavaissiere L, Mock P, Laurent A, Sabourin JC, Bedossa P, Le Bouteiller P, Frydman R, Troalen F\& Bidart JM 1997 Identification of pro-EPIL and EPIL peptides translated from insulin-like 4 (INSL4) mRNA in human placenta. Journal of Clinical Endocrinology and Metabolism 82 3169-3172.

Brandt B, Roetger A, Dittmar T, Nikolai G, Merschjann A, Nofer J-R, Assmann G \& Zaenker KS 1999 c-erbB-2/EGFR as dominant heterodimerization partners determine a motogenic phenotype in human breast cancer cells. FASEB Journal 13 1939-1949.

Brandt B, Roetger A, Bidart J-M, Packeisen J, Schier K, Mikesch J-H, Kemming D, Boecker W, Yu D \& Buerger H 2002 Early placenta insulin like growth factor (pro-EPIL) is overexpressed and secreted by c-erbB-2 positive cells with high invasion potential. Cancer Research 62 1020-1024.

Chassin D, Laurent A, Janneau JL, Berger R \& Bellet D 1995 Cloning of a new member of the insulin gene superfamily (INSL4) expressed in human placenta. Genomics 29 465-470.

De Potter CR \& Schelfhout AM 1995 The neu-protein and breast cancer. Virchows Archiv 426 107-115.

Dittmar T, Husemann A, Schewe Y, Nofer J-R, Niggemann B, Zänker KS \& Brandt BH 2002 Induction of cancer cell migration by epidermal growth factor is initiated by specific phosphorylation of tyrosine 1248 of c-erbB-2 receptor via EGFR. FASEB Journal 16 1823-1825.

Gilmore AP, Valentijn AJ, Wang P, Ranger AM, Bundred N, O'Hare MJ, Wakeling A, Korsmeyer SJ \& Streuli CH 2002 Activation of BAD by therapeutic inhibition of epidermal growth factor receptor and transactivation by insulin-like growth factor receptor. Journal of Biological Chemistry 277 27643-27650.

Graus-Porta D, Beerli RR, Daly JM \& Hynes NE 1997 ErbB-2, the preferred heterodimerization partner of all erbB receptors, is a mediator of lateral signaling. EMBO Journal 16 1647-1655. 
Guidi A, Laricchia-Robbio L, Gianfaldoni D, Revoltella R \& Del Bono G 2001 Comparison of a conventional immunoassay (ELISA) with a surface plasmon resonancebased biosensor for IGF-1 detection in cows' milk. Biosensors and Bioelectronics 16 971-977.

Hombach-Klonisch S, Buchmann J, Sarun S, Fischer B \& Klonisch T 2000 Relaxin-like factor (RLF) is differentially expressed in the normal and neoplastic human mammary gland. Cancer 89 2161-2168.

Irvine RF \& Schell MJ 2001 Back in the water: the return of the inositol phosphates. Nature Reviews in Molecular and Cellular Biology 2 327-338.

Katterle Y, Brandt BH, Dowdy SF, Niggemann B, Zänker KS \& Dittmar T 2004 Effective inhibition of EGF induced cell migration of EGFR/c-erbB-2 positive breast cancer cells using a recombinant PLC- $\gamma 1-(\mathrm{SH} 2) 2-$ TAT protein. British Journal of Cancer 90 230-235.

Mann CJ, Stephens SK \& Burke JF 2004 Production of protein microarrays. In Protein Microarray Technology. Ed. D Kambhampati. Wiley-VCH.

Mock P, Frydman R, Bellet D, Diawara DA, Lavaissiere L, Troalen F \& Bidart JM 1999 Pro-EPIL forms are present in amniotic fluid and maternal serum during normal pregnancy. Journal of Clinical Endocrinology and Metabolism 84 2253-2256.

Rasmussen AA \& Cullen KJ 1998 Paracrine/autocrine regulation of breast cancer by insulin-like growth factors. Breast Cancer Research and Treatment $\mathbf{4 7}$ 219-233.

Roetger A, Merschjann A, Dittmar T, Jackisch C, Barnekow A \& Brandt B 1998 Selection of potentially metastatic subpopulations expressing c-erbB-2 from breast cancer tissue by use of an extravasation model. American Journal of Pathology 153 697-1860.

Roundabush FL, Pierce KL, Maudsley S, Khan DK \& Luttrell LM 2000 Transactivation of the EGF receptor mediates IGF-1-stimulated Shc phosphorylation and erk $1 / 2$ activation in COS-7 cells. Journal of Biological Chemistry 275 22583-22589.

Schelfhout VR, Coene ED, Delaey B, Thys S, Page DL \& De Potter CR 2000 Pathogenesis of Paget's disease: epidermal heregulin-alpha, motility factor, and the HER receptor family. Journal of the National Cancer Institute 92 622-628. 
